\title{
Strategies for encouraging the abandonment of female genital cutting in West Africa: Experiences from Senegal, Burkina Faso, and Mali
}

Nafissatou J. Diop

Population Council

Ian Askew

Population Council

Follow this and additional works at: https://knowledgecommons.popcouncil.org/departments_sbsr-rh

Part of the Community-Based Research Commons, Community Health and Preventive Medicine Commons, Gender and Sexuality Commons, International Public Health Commons, Obstetrics and Gynecology Commons, Public Health Education and Promotion Commons, and the Women's Health Commons

How does access to this work benefit you? Let us know!

\section{Recommended Citation}

Diop, Nafissatou J. and lan Askew 2006. "Strategies for encouraging the abandonment of female genital cutting in West Africa: Experiences from Senegal, Burkina Faso, and Mali," in Rogaia Mustafa Abusharaf (eds.), Female Circumcision: Multicultural Perspectives. Philadelphia: University of Pennsylvania Press. 
Female

Circumcision

Multicultural Perspectives

Edited by

Rogaia Mustafa Abusharaf 


\section{Chapter 6}

\section{Strategies for Encouraging the Abandonment of Female Genital Cutting: Experiences from Senegal, Burkina Faso, and Mali Nafissatou J. Diop and Ian Askew}

The understanding, cooperation, determination, and know-how of the principal participants in circumcision are imperative for a workable solution. Programs tempered with an interest in, and respect for, grassroots initiatives and local knowledge of needs which are designed, delivered, and managed by the community women have a better prospects of sustainability.

-L. Amede Obiora, 1997

What we call Female Genital Cutting (FGC) is prevalent in much of West Africa, and grassroots activists, nongovernmental organizations (NGOs), and national committees are working together to end it. This essay evaluates strategies employed to encourage the abandonment of FGC in three adjacent nation-states: Mali, Burkina Faso, and Senegal. The proportions of the population practicing FGC vary both between countries and within them. FGC is almost universal (92 percent) in Mali (CPS/MS, DNSI, and Macro International 2002), and it is widespread ( 72 percent) in much of Burkina Faso (INSD and Macro International 2000). In Senegal, where the national prevalence rate is estimated to be 20 percent (Mottin-Sylla 1990), the practice is restricted to some ethnic groups (Fulani, Mandingo, and Soninké, among others), and among them the prevalence rate is high (80-90 percent).

The rationales given for this practice in West Africa and the underlying social and cultural reasons for its continuation are similar to those found in 
of the disadvantages of continuing FGC. Translating this knowledge into behavior requires a sequence of components to follow this first stage, which are usually implemented community-wide, to build the commitment of the majority of families to decide not to allow their daughters to be cut, to implement that decision despite opposition from others, and then to ensure that they sustain this change over time (Izett and Toubia 1999, Mackie 2000).

First we consider evaluations of two strategies that focus on changing the behavior of individuals who play key roles in the practice of FGC: traditional practitioners who carry out the genital cutting; and health care providers who work in medical settings and may perform the procedure themselves or support others who do. Second, we present the findings from an evaluation of one of the best-known examples of a community-wide behavior change strategy, the Village Empowerment Program developed by the Senegalese NGO, Tostan.

\section{Traditional Practitioners}

The vast majority of girls in Mali, Burkina Faso, and Senegal who undergo FGC are cut by traditional practitioners, usually called excisors: 91 percent in Mali, 97 percent in Burkina Faso, and 93 percent in Senegal. Excisors usually carry out the cutting with crude implements and in unhygienic conditions, so the health risks of the procedure are easily highlighted during educational campaigns. Traditional practitioners are obvious targets for efforts to encourage abandonment of the practice, but only if it can be assumed that a strategy to decrease the supply of those doing the cutting will also reduce demand for the service.

In Mali, several NGOs have developed and implemented strategies that seek to persuade traditional practitioners to stop agreeing to cut girls. The Centre National de la Recherche Scientifique et Technologique (CNRST, the National Center for Scientific and Technological Research) and the Population Council undertook an evaluation of the programs of the three main organizations using this strategy: the Association Malienne de Suivi et d'Orientation des Pratiques Traditionelles (AMSOPT, the Malian Association for Monitoring Traditional Practices), the Asscziation pour le Progrès et la Défense des Droits des Femmes (APDF, the Association for the Progress and Defense of Women's Rights), and the Association de Soutien au Développement des Activités de Population (ASDAP, the Association for the Development of Population Activities). 
In brief, the strategies followed by the three NGOs comprised the same two initial phases:

- Identifying traditional practitioners and educating them on the physiology of female genitalia, the harmful consequences of FGC, and their role in perpetuating it.

- Raising awareness of the harmful consequences of FGC in communities.

Because excisors gain social status from performing the procedure and may be dependent on the remuneration they receive from it, two of the NGOs developed alternative income-generating activities for practitioners, and one of them also provided excisors with financial assistance. Similar to the Sudan National Committee on the Eradication of Traditional Practices Harmful to Women and Children, one NGO educated practitioners to become change agents within their communities.

To evaluate this strategy, data were collected through interviewing the heads of the three NGOs, 10 field staff members, and 41 practitioners. In addition, 45 focus group discussions were conducted with 380 community members in six of the districts where the NGOs operate. The study sought to understand the content and means of communicating messages to the practitioners, determine community attitudes following implementation, and assess the efficacy of these strategies (Population Council and CNRST 1998).

\section{Health Care Providers}

In several countries, many families now seek the services of medical professionals in an attempt to avoid the dangers of unskilled practitioners performing FGC in unsanitary conditions (for Guinea, see Yoder et al. 1999; for Egypt, see El-Gibaly et al. 2002; for Nigeria, see Mandara 2000; for Kenya, see Shell-Duncan et al. 2000, Njue and Askew 2004, and Jaldesa et al. 2005). Health care workers find themselves under pressure from individuals and families to carry out FGC. While those who support the practice may willingly accede to the request, even those who do not may find the financial incentive hard to resist. Medicalizing the procedure constitutes a violation of a girl's right to bodily integrity and does not address the long-term sexual, reproductive, and mental health complications that may result from FGC. Virtually all international organizations are unequivocal in their opposition to medical providers engaging in the practice, and several are working to 
engage health care providers actively to oppose FGC within their clinics and communities (WHO 2001). Most importantly, this trend toward medicalization is contrary to the WHO statement that "female genital mutilation in any form should not be practiced by health professionals in any setting" (WHO 2001). Numerous other organizations have made explicit statements against medicalization, including the International Federation of Gynecology and Obstetrics, the Inter-African Committee, and the U.S. Agency for International Development (USAID). They unequivocally declare that no health professional should practice FGC in any setting-including nurses and midwives as well as physicians, and clinics as well as hospitals (WHO 1997). However, the issue remains contentious and complex (Shell-Duncan 2001; Shell-Duncan et al. 2000).

Health care providers interact regularly with people from diverse backgrounds and have the opportunity to discuss the health implications of FGC with their clients, as well as to identify and deal with medical problems arising from circumcision. They constitute an underutilized and potentially important resource in educational campaigns against FGC. In 1998, ASDAP, the Malian Ministry of Health's Department for Community Health, and the Population Council developed and pilot-tested an intervention that consisted of two main activities:

- Training clinic staff in identifying the types of FGC and related health complications and in communicating messages against FGC to their clients.

- Introducing FGC topics within group health talks at the clinics and during individual consultations with clients whenever feasible.

During three days of training, providers were given information on the prevalence of FGC, reasons for the practice, female anatomy, types of cutting, complications that result from the procedure, and how complications can be managed. Participants spent an entire day learning how to do counseling and give health talks, using role-playing and a flipchart developed specifically for this purpose.

The intervention was evaluated in terms of the extent to which these activities improved providers' understanding of FGC-related health problems, increased the proportion of them identifying and managing such complications, and reduced the likelihood of their agreeing to cut girls. The study also measured whether clients were more likely to hear messages against FGC after the training. The interventions were implemented by training a team of 
master trainers (eight doctors and two midwives) and developing a special set of educational materials. In turn, the master trainers trained 59 staff in eight clinics. These providers were then compared over time with 49 providers drawn from six similar clinics. Both sets of clinics were located in the capital city of Bamako and in the rural region of Ségou. The knowledge, attitudes, and actions of practitioners were measured immediately before the training and three months afterwards through interviews with providers and observations of group health talks in the clinics. Interviews were held with 1,633 clients to assess their exposure to FGC messages during their consultation (Diop et al. 1998).

\section{Village Empowerment}

The Village Empowerment Program (VEP), also known as the Tostan program after the international NGO based in Senegal that developed it, ${ }^{2}$ evolved out of a functional literacy program for women that seeks not only to equip women with knowledge and skills for personal development but also to empower them to participate more actively in community development, a field traditionally reserved for men. This program was developed with the philosophy that literacy skills alone are not sufficient to prepare learners for active participation in the social, political, economic, and cultural decisions related to the development of their community and ultimately their country (Tostan 1999). Tostan promotes an integrated approach to learning, offering a comprehensive curriculum in national languages not only for reading, writing, and mathematics, but also for improving life skills and the socioeconomic conditions of participants. The use of innovative pedagogical techniques inspired by African traditions and local knowledge has contributed to making the sessions relevant, lively, and participatory.

The program consists of two interrelated components: a basic education program to raise women's functional literacy, and through this to advance their understanding of reproductive health and basic human rights; and an awareness-raising and social mobilization process to educate local leaders and the whole community about the harmful consequences of FGC and encourage them to make a public declaration in favor of its abandonment. Classes of approximately 30 women per village study four moduleson human rights, hygiene, problem solving, and women's health-over a period of seven to eight months. Recently, in response to their requests, Tostan has added classes for men, held separately but at the same time. Social 
mobilization activities are undertaken within each village, and then several villages are gathered together in order to debate issues concerning FGC, early marriage, and the use of family planning. Village committees play a key role in organizing these meetings, and women involved in the literacy program and their facilitators are bringing the issues to the debates.

The Population Council evaluated the effectiveness of the VEP in two different but comparable situations: in the Kolda region of southern Senegal, where Tostan has expanded its existing program into 90 villages; and in the Bazega province of central Burkina Faso, where Tostan has mentored a national community development NGO called Mwangaza to implement the VEP in 23 villages. Both studies were financially supported by the German organization Gesellschaft für Technische Zusammenarbeit (GTZ) and the United States Agency for International Development (USAID).

To test the effect of the basic education program and the social mobilization process on community members' attitudes toward FGC and on their willingness to hold a public meeting to declare community-wide abandonment of the practice, which is used as the ultimate indicator of social change, both studies compared these indicators before and after introducing the intervention, and compared the study villages with similar villages where the intervention was not introduced. During surveys carried out immediately before and 12 months after the interventions were introduced, all women who participated in the programs were interviewed (approximately 600 women in Senegal and 580 women in Burkina Faso). In addition, the majority of their husbands or partners and a sample of women living in the same villages who did not participate in the education program were interviewed to gain an understanding of the degree to which the intervention had diffused beyond those directly participating in the program.

Key Findings from the Evaluation Studies

Traditional practitioners continue to perform FGC despite making statements that they had abandoned the practice.

Attempts to convince traditional practitioners to give up the practice were not successful. FGC was still being performed in all but one of the six sites visited for the evaluation, and in that site it had not been performed for the past two years only because it was not the customary time for circumcision. Most people did not know of any excisors who had stopped working, as they 
were still responding to requests from families. Out of 41 excisors interviewed, 29 declared that although they had been sensitized by the NGO, they were still performing the procedure when requested and were not convinced that what they were doing is wrong. Others explained that they had given up the practice but took it up again because the NGO did not provide them with the alternative sources of income they had been promised. The five practitioners who had genuinely discontinued FGC actually did so for reasons unrelated to the intervention: they retired because of advanced age or poor eyesight and were replaced by their daughters. Most practitioners remained unconvinced that FGC is harmful to women, and community members had no difficulty finding a replacement for any excisor who gave up the practice, either through another traditional practitioner or a health provider (Population Council and CNRST 1998).

Most health providers are opposed to FGC and are willing to play an active role in discouraging the practice. But many remain supportive, and several continue to perform the procedure in medical facilities.

Interventions targeted at health care professionals who work in medical settings have been more successful in influencing their knowledge and attitudes than in changing behavior. After training, the majority of health providers (62 percent) supported efforts to encourage the abandonment of FGC in principle. The beliefs that uncut girls are immoral, that men prefer cut girls, and that FGC guarantees virginity until marriage decreased slightly among providers as a result of training. Nevertheless, 28 percent of them said that they were not really against the practice, and another 10 percent indicated support for its medicalization. While no training intervention is likely to influence the beliefs and attitudes of all health providers, this intervention did succeed in changing the opinions of 47 percent of the providers. A significant number (13 percent) recognized that FGC is being practiced at their facility, although understandably, very few ( 2 percent) admitted performing the procedure themselves.

The gap between what providers know is happening and what they admit to doing is as telling as the apparent medicalization of this harmful practice is alarming. Unless providers who actively oppose the practice persuade their colleagues to refuse to perform it, little headway will be made toward its abandonment. As a direct consequence of this research finding, the Malian Ministry of Health immediately issued a policy directive to all its providers explicitly banning the practice by $\mathrm{MOH}$ employees and in $\mathrm{MOH}$ premises. 
The Ministry of Women's Affairs also circulated a decree to all its central and local service providers that they should be aware of the $\mathrm{MOH}$ policy and do their best to promote and reinforce it.

Although providers' knowledge of FGC increased as a result of training, they remained uncomfortable discussing FGC with their clients.

The dramatic gains in health providers' factual knowledge of the various types of FGC did not translate into their taking actions to discourage it among their clients. The proportion of providers who believed that FGC poses no significant risk to women's health did not decrease much as a result of training, suggesting that medical information did not erase their support for the practice. Those professionals who were opposed to FGC and well aware of its health risks found few opportunities to talk with their patients about it. Most providers indicated that, because of the large number of clients during the morning clinic sessions, they felt too rushed to be able to spend time discussing FGC with their patients. Indeed, during exit interviews only 0.5 percent of women said that they had been counseled about FGC.

More than one third of providers interviewed had referred a client for further treatment of complications resulting from FGC. Although health professionals are better able to recognize those complications, providers acknowledged that they have limited competence in treating them and would appreciate further training. Since completion of this study, USAID has supported a training program in Mali to strengthen providers' skills in managing FGC-related complications and in educating their clients on the benefits of abandoning the practice. This program, implemented by IntraHealth's PRIME II Project, resulted in an increase in knowledge of FGC, with nearly three quarters of providers passing the test on counseling skills, up from 12 percent at the baseline (Newman and Nelson 2003).

The Village Empowerment Program improved knowledge and attitudes concerning reproductive health, human rights, and gender relations.

Women who participated in the basic education program in Senegal showed tremendous improvements in their awareness of reproductive health, human rights, and gender relations and substantial shifts in their attitudes toward FGC. The data demonstrate that women living in these villages who did not directly participate in the education program also gained greater 
awareness of these issues. Similar increases were found among men living in these villages, suggesting that the education program can also influence others, perhaps through discussions between participants and nonparticipants which are actively encouraged by Tostan as part of the implementation process.

The Village Empowerment Program decreased the practice of FGC.

Participation in the Village Empowerment Program had significant positive effects in reducing the practice of FGC. For example, the prevalence of FGC reported among daughters under 11 years of age decreased significantly among women who participated in the program (from 54 to 40 percent). Rates of FGC also declined among the daughters of women in these villages who did not participate directly in the program. The girls who were cut, however, were now being cut at younger ages than before, suggesting that those who chose to continue the practice were taking steps to ensure that the girls would definitely be cut before they could oppose the decision. This finding, although not the main effect of the intervention, is a matter of some concern.

Social mobilization has been successful in leading to public declarations against FGC, as well as supporting other improvements in the position of women in civil society.

In both Senegal and Burkina Faso, social mobilization strategies have been used to build on this increased awareness in the villages by seeking to shift group attitudes in order to change behavior. Following these group discussions within the 90 villages in Senegal, these and over 200 other communities were brought together and publicly declared, during a specially organized event in the town of Karcia, that they would no longer practice FGC on their daughters. The additional villages participated because reconsideration of the value of FGC had diffused widely through participants' networking with their friends and relatives in other villages where the VEP program had not been introduced. Also, each intervention village conducted social mobilization activities in two other villages of their choice.

In addition to building a community-wide consensus to declare an end to FGC, the social mobilization strategy facilitated several other initiatives that have improved the position of women and girls in civil society. In Burkina Faso, the 23 project villages led movements to enroll girls in school, to 
register children so that they can get identity cards, and to organize campaigns for massive voter registration. For example, in one village 43 couples decided to get married legally; in another 10 villages it was decided that all families should receive an official family record book; and in all 23 villages environmental hygiene and health activities to improve living conditions were undertaken (Diop et al. 2003).

\section{Lessons Learned}

Understanding the ways in which a community consensus in favor of FGC is sustained and can be overturned in practice enables grassroots activists, NGOs, international agencies, and all those concerned with ending this violation of women's rights to bodily integrity to identify appropriate and effective strategies for social change. Without systematic research, the causeand-effect relationships between intervention activities and desired outcomes are seldom clear (Izett and Toubia 1999). Integrating evaluation studies into the design of interventions need not be complex or burdensome (see Population Council 2002 for a discussion of the key issues to be considered with this type of research). This approach does, however, require a commitment to two principles: that an intervention's effectiveness cannot be assumed simply because it is feasible and acceptable to the community; and that its effectiveness cannot be measured or demonstrated without a quasiexperimental study design. Pilot-testing strategies for encouraging the abandonment of FGC and evaluating their effectiveness can be a crucial step in developing a successful program of action that can then be implemented on a larger scale. The empirical information collected and insights generated through carefully documenting the process of implementing a strategy and systematically measuring its effectiveness provides those responsible for developing, implementing, and funding anti-FGC programs with concrete evidence of what works, what does not, and why. These research studies offer many lessons for decision makers at various levels to consider when developing strategies appropriate for their particular context.

The strategy of encouraging traditional practitioners to stop performing FGC and to become change agents is not effective because so few give up the practice permanently. The excisor is a community member, and her stopping the practice depends on the level of awareness within the community that FGC contravenes basic rights and can be harmful. As long as there is still community-level support for the practice, parents will continue to seek 
someone to do the cutting, so it is much easier for an excisor to continue her practice than to stop. The low social status and relative poverty of traditional practitioners make the recognition they gain and the livelihood they earn through performing the procedure valuable personal assets. Since it is in their interest to continue the practice, they are in no position to influence the community to abandon FGC. Programs intended to furnish them with alternative sources of income have not been successful, as any alternative would also have to provide them with a level of social recognition similar to that enjoyed as a practitioner.

In these West African societies, the power to influence community-wide behavior is vested in the chiefs and elders, so anti-FGC strategies must address community support for the practice by persuading these groups to advocate against it, rather than trying to cut off the supply of practitioners with the expectation that this will also curtail demand. The results of this evaluation are similar to what has been observed in northeastern Africa, which led the WHO to recommend that "while excisors should be included in programming, finding alternative income for excisors should not be the major strategy for change" (WHO 1999).

The strategy of working with health care providers had two components: training them in basic skills to manage FGC-related medical complications; and educating them to become active advocates against the practice during consultations with their clients. There was a clear need to train health staff to recognize medical problems induced by FGC and to provide the specific care needed. Health professionals' lack of knowledge reflected the general lack of public awareness of the linkages between women's reproductive health and the practice of FGC. Even relatively simple training significantly improved health care providers' levels of knowledge about FGC and its complications. Consequently, it was recommended that such training be incorporated into preservice medical training. It was not possible to document whether the training improved management of complications, but the proportion of providers identifying complications and referring patients for treatment increased. The research suggests that such training is essential in countries where gynecological and obstetrical complications due to FGC are widespread.

The strategy of using health care providers is compromised, however, by the fact that many of them support the practice, and in some cases actually cut girls themselves. For providers to be able to encourage change among their clients and the broader community, they themselves must first go through a process of attitudinal and behavioral change. Any strategy focused 
on using health professionals to convince communities to abandon FGC that does not begin with real changes in their own attitudes and actions will not achieve its objectives. Even those health care providers who are well informed about the negative medical consequences of FGC do not necessarily pass on that information to their clients. Given their status in the community and influence over their patients, heath providers are an important potential resource in campaigns to abandon FGC, but a concerted and wellplanned effort is needed to ensure that they become effective change agents. Training for health care professionals must be supported and extended by broader efforts at the community level.

The use of community-based strategies like the Village Education Program (VEP) show real promise, as their multifaceted approach addresses knowledge, attitudes, actions, and communal support in an integrated manner. A comprehensive education program that includes human rights, reproductive health, and gender relations and is coupled with strategies that give women more confidence and empower them to participate in communitylevel discussions and activities concerning their bodily health and their position in society is more likely to lead to changes in social behavior. The participatory methods used in the basic education program create an opportunity for self-determination; women themselves decide which actions they and the wider community should take. Because education on human rights and gender relations was included along with information about FGC, women understand that this practice is not merely an individual concern or a health-related problem but must be viewed as an integral component of their rights, their roles in society, and community development.

The VEP strategy builds on the fact that in these village-based societies, as is the case across rural Africa, a public declaration is more powerful than individual expressions of opinion about a socially approved practice. According to the sociological principles on which the VEP is based (Mackie 2000), these declarations are the most important factors facilitating abandonment of the practice. Put briefly, the normal lack of public discussion or debate about the practice of FGC makes it difficult for individual families to judge the opinions and expectations of others within their community, so they remain uncertain and anxious about others' attitudes when their own attitudes have shifted. Until the subject is brought into the open, people will not risk damaging their reputation by ceasing to practice FGC. Mackie argues that the most important reference group against which people judge their decision is not the community as a whole but the social grouping within which the family marries, since FGC is seen as a prerequisite for making a socially acceptable 
match. Thus, if there is a critical mass of families within a community, or within a group of intermarrying families, who have individually come to the decision that they would like to abandon FGC, then holding a public declaration against the practice by their representatives enables each of them to know that a critical mass of significant others holds the same view. What may have been perceived as a minority view is now known to be a majority view and becomes the new social convention for that group.

Two key unknowns play important roles in promoting or inhibiting this process of change. First, how can individuals and families become sufficiently concerned about the harms entailed in FGC that they seriously contemplate changing their behavior? Is educating a group of 30 women in a village through a functional literacy program enough, at least when undertaken together with social mobilization activities organized by an NGO? Secondly, how can an NGO actively support and organize a public declaration so that it represents a sincere and widespread pledge that the majority of the community will change its actions? The public declaration in Karcia, Senegal, included many more villages than had participated in the VEP. Can villages that did not participate in the VEP be expected to be at the same stage in the behavior change process as villages that participated directly in the program? In order to understand the diffusion process, we must know more about the ways in which the other villages became involved in the public declaration activity. Evidence (Diop et al. 2004) suggests that this involvement was strongly based on familial and friendship ties among the leaders of different villages - that is, on the dynamics of intermarriage within the geographic area. More research is needed on the information diffusion process that takes place among village leaders and on the role of these leaders within their villages as communicators of ideas for change.

\section{Conclusion}

Since community-based programs to encourage the abandonment of FGC are relatively new and deal with a sensitive and deeply embedded cultural practice, it is crucial that the strategies they employ are based on a comprehensive understanding of the values, beliefs, practices, and rules of social interaction that prevail at the community level. The lack of a theoretical and empirically tested sociological model informing the strategies targeting traditional practitioners and health care professionals may well explain their relative ineffectiveness. Those who perform FGM and provide health care are 
not easily persuaded to become advocates of change, and the health care practitioners who oppose FGM evidently do not exercise the kind of influence that these programs assume. In order to be effective, strategies should be designed to generate social change rather than merely influence individuals, and they must offer social support for families to carry their new ideas through action. FGC is usually undertaken to prepare daughters for marriage in compliance with what is perceived to be a social convention in the communities within which marriages take place. The VEP approach seeks to initiate and support a community-wide behavior change process. Its demonstrated effectiveness appears to support the theory that changing social behavior requires building a community-wide agreement that such a practice is not desirable and then publicizing and demonstrating widespread agreement with this change through a pledge ceremony. The way forward lies in implementing interventions that are based on a thorough understanding of the communities involved and on facilitating grassroots involvement in the process of social change. 